\title{
Genetic Variation among Cucurbita pepo Accessions Varying in Seed Nutrition and Seed Size
}

\author{
Geoffrey Meru, Dayana Leyva, Vincent Michael, Riphine Mainviel, Marie Dorval, Yuqing Fu \\ Horticultural Sciences Department and Tropical Research and Education Center, University of Florida, Homestead, FL, USA \\ Email: gmeru@ufl.edu
}

How to cite this paper: Meru, G., Leyva, D., Michael, V., Mainviel, R., Dorval, M. and Fu, Y.Q. (2019) Genetic Variation among Cucurbita pepo Accessions Varying in Seed Nutrition and Seed Size. American Journal of Plant Sciences, 10, 1536-1547. https://doi.org/10.4236/ajps.2019.109109

Received: August 16, 2019

Accepted: September 14, 2019

Published: September 17, 2019

Copyright $\odot 2019$ by author(s) and Scientific Research Publishing Inc. This work is licensed under the Creative Commons Attribution International License (CC BY 4.0).

http://creativecommons.org/licenses/by/4.0/

(c) (i) Open Access

\begin{abstract}
Pumpkin seed (Cucurbita pepo L.) is a nutritionally valuable food and a significant source of income globally. Pumpkin seeds are rich in oil, protein, unsaturated fatty acids and tocopherols, which are associated with improved human health. Understanding the genetic diversity among pumpkin accessions varying in seed nutrition traits is necessary for designing sound breeding strategies for developing superior cultivars. In the current study, 26 simple sequence repeats (SSR) markers were used to assess genetic relatedness among 29 C. pepo accessions varying in seed oil, seed protein, seed-coat phenotype, seed size and fatty acid composition. The SSR markers revealed 102 alleles averaging 3.92 alleles per loci and mean polymorphic information content (PIC) of 0.44 . Eleven of the markers had a PIC of $\geq 0.5$. Ward dendrogram and principle component analysis based on seed traits grouped the genotypes into two major clusters corresponding to subspecies pepo and texana, with all the reduced-hull accessions grouping within the former. Collectively, this data suggests wide phenotypic (seed traits) and genotypic variation within C. pepo that may be exploited to develop superior reduced-hull cultivars.
\end{abstract}

\section{Keywords}

Pumpkin, Seed Oil, Seed Protein, Fatty Acid Composition, Seed Size, SSR Markers, DNA, Alleles, Phylogenetic Tree, Genetic Distance

\section{Introduction}

Pumpkin (Cucurbita pepo) seed is an important source of nutrition and income in many countries around the world [1] [2] [3]. Pumpkin seed is rich in oil (>50\% 
$\mathrm{w} / \mathrm{w}$ ) and is commercially exploited for production of high-premium vegetable oil, which is popular in Europe and Asia [4]. The seed is rich in phytonutrients that are associated with several health-promoting benefits. For example, the high level of unsaturation in the oil (>86\%) [5] is linked to a reduced risk for arteriosclerosis and heart-related ailments [6], while the antioxidants (tocopherols and tocotrienols) are associated with lowered risk for gastric, breast, lung, and colorectal cancer [7] [8] [9]. Pumpkin seed contains phytosterols, which are structurally similar to cholesterol, thus compete with body's cholesterol for absorption, hence playing a key role in lowering cholesterol levels and treatment of benign prostate hyperplasia [2] [10]. Furthermore, due to its high protein content (35\%) [2], pumpkin seed is also commonly used in animal feed to augment protein levels [4].

In the U.S., pumpkin seeds are popular in trail mix snacks, as well as an ingredient in various foods and drinks [1] [11]. Pumpkin seed oil is sold in many health-food stores across the country [9]. As the market for niche healthy foods increases in the U.S., a concomitant increase in the demand for pumpkin seed and allied products is expected. Pumpkin seeds with reduced-hulls (hull-less) are preferred for snacking and oil production because they eliminate the need for de-hulling prior to use [7]. Although pumpkin cultivars with reduced-hull are commercially available in the U.S., they lack marketable fruit quality, often characterized by bland or bitter flesh and undesirable off-white color [12]. Consequently, these pumpkins are not popular among U.S. growers whose primary market requires superior flesh quality characterized by high brix, good flavor and orange color. As a result, a majority of reduced-hull seeds consumed in the U.S. are imported [12]. To expand the local supply of reduced-hull pumpkin seed in the U.S., it is important for plant breeders to develop dual-purpose pumpkins for use in both the production of hull-less seeds, as well as marketable flesh.

A key goal of the cucurbit breeding program at the University of Florida is to develop dual-purpose (reduced-hull and marketable flesh) pumpkins for the U.S. market by exploiting the wealth of genetic diversity within $C$. pepo. Initial assessment of the seed nutrition profile among 35 accessions of $C$. pepo revealed wide variation in oil $(29.3 \%-48.4 \%)$, protein $(19.4 \%-31.3 \%)$, and fatty acid content [palmitic $(6.7 \%-12.6 \%)$, stearic $(3.3 \%-7.6 \%)$, oleic $(18.4 \%-46 \%)$ and linoleic $(35.4 \%-64.1 \%)]$ and seed size [(seed length $(9.94-19.33 \mathrm{~mm})$, seed width $(6.74-10.38 \mathrm{~mm})$, and 10 seed weight $(0.16-2.87 \mathrm{~g})$ ] [5]. The 35 accessions included 26 Pumpkin, 4 Acorn, 1 Zucchini, 2 Straightneck and 2 Crookneck accessions, 26 of which had reduced-hulls, while nine had hulled seed phenotype. Information on the genetic diversity and multivariate patterns of phenotypic variation among these accessions would inform our breeding program best strategies for improving flesh quality and enhancing seed nutrition for dual-purpose pumpkins.

Previous genetic diversity studies in $C$. pepo have utilized a variety of marker types including allozymes, random amplified polymorphic DNA, amplified fragment length polymorphism, sequence-related amplified polymorphism, inter-simple sequence repeats, high frequency oligonucleotide-targeting active gene and simple 
sequence repeats (SSR) [13]-[19]. Among these, SSR markers are preferred due to high level of polymorphism, codominance and reproducibility [20] [21]. Principal component analysis (PCA) [22] on the other hand is a useful tool for exploring phenotypic variation to identify superior parents for use in crossing nurseries [23].

The goal of the current study was to use SSR markers to determine the genetic diversity within a set of 35 C. pepo accessions varying in seed nutrition and seed size traits. In addition, the accessions were subjected to PCA to identify patterns of variation in seed nutrition and seed size traits to aid in selection of superior parents.

\section{Materials and Methods}

\subsection{Plant Material and DNA Extraction}

The 35 C. pepo accessions used in the current study were those analyzed for seed nutrition and seed size traits in our previous study [5]. Among these, six did not germinate or lacked seeds. Therefore, only 29 accessions were used for genetic diversity analysis, and included 22 Pumpkin, 2 Acorn, 2 Straightneck, 1 Zucchini and 2 Crookneck cultivars [5]. For each accession, five seeds were germinated in the greenhouse, and at the two true-leaf stage, three leaf punches were collected from three individuals and immediately frozen in liquid nitrogen. DNA was extracted using the E.N.Z.A kit (Omega Biotek, Norcross, GA) according to the manufacturer's instructions.

\subsection{SSR Amplification and Allele Scoring}

Twenty-six SSR primer pairs for C. pepo were used for diversity analysis (Table 1) [24]. Each $15 \mu \mathrm{l}$ PCR reaction contained $40 \mathrm{ng}$ template DNA, $0.32 \mu \mathrm{M}$ of a fluorescently (6-FAM, VIC or PET) labeled M13 forward primer (GCCTCCCTCGCGCCA) [25], $0.04 \mu \mathrm{M}$ of M13-tagged forward primer, $0.4 \mu \mathrm{M}$ unlabeled reverse primer, and $1 \mathrm{X}$ PROMEGA colorless GoTaq mastermix (Promega, Madison, WI). Amplification was performed in 96-well plates on a SimpiAmp thermal-cycler (Applied Biosystems, Foster City, CA) using an initial 3 min denaturation, followed by 35 cycles of $15 \mathrm{~s}$ at $95^{\circ} \mathrm{C}, 20 \mathrm{~s}$ at $52^{\circ} \mathrm{C}$, and $30 \mathrm{~s}$ at $72^{\circ} \mathrm{C}$. The amplification was followed by a final extension step of $10 \mathrm{~min}$ at $72^{\circ} \mathrm{C}$. The amplicons for three primer pairs, each labeled with a different fluorescent dye, were multiplexed and combined with a GeneScan-500 ROX internal-lane size standard and formamide before analysis on a 3730 96-capillary DNA Analyzer (Applied Biosystems) at the Gene Expression and Genotyping Core facility, University of Florida. GeneMarker software (SoftGenetics, State College, PA) was used for allele calling and size estimation.

\subsection{Genetic Diversity Analysis}

Pairwise dissimilarity matrix was calculated using Darwin software (v6.0) by Simple Matching coefficients with minimal proportion of valid data for each unit pair set to $90 \%$ [26]. The Ward method was used for cluster analysis [27] using 
Table 1. Summary statistics of 26 SSR used for genetic diversity analysis among $29 \mathrm{Cu}$ curbita pepo accessions.

\begin{tabular}{|c|c|c|c|c|c|c|}
\hline SSR name & $\begin{array}{l}\text { Major allele } \\
\text { frequency }\end{array}$ & $\begin{array}{c}\text { Genotype } \\
\text { number }\end{array}$ & $\begin{array}{c}\text { Allele } \\
\text { number }\end{array}$ & Gene diversity & Heterozygosity & PIC \\
\hline CMTp133 & 0.31 & 10.00 & 7.00 & 0.79 & 0.28 & 0.75 \\
\hline CMTp177 & 0.45 & 8.00 & 7.00 & 0.72 & 0.69 & 0.68 \\
\hline CMTp129 & 0.38 & 8.00 & 4.00 & 0.72 & 0.25 & 0.67 \\
\hline CMTp205 & 0.46 & 9.00 & 7.00 & 0.71 & 0.23 & 0.67 \\
\hline CMTp176 & 0.47 & 7.00 & 5.00 & 0.69 & 0.10 & 0.65 \\
\hline CMTp206 & 0.44 & 5.00 & 4.00 & 0.66 & 0.12 & 0.59 \\
\hline CMTp127 & 0.57 & 6.00 & 5.00 & 0.62 & 0.03 & 0.59 \\
\hline CMTp178 & 0.39 & 5.00 & 3.00 & 0.66 & 0.29 & 0.58 \\
\hline CMTp224 & 0.60 & 7.00 & 6.00 & 0.60 & 0.10 & 0.57 \\
\hline СМТр249 & 0.62 & 7.00 & 4.00 & 0.57 & 0.12 & 0.53 \\
\hline CMTp141 & 0.55 & 8.00 & 4.00 & 0.58 & 0.41 & 0.51 \\
\hline CMTp77 & 0.63 & 6.00 & 5.00 & 0.52 & 0.18 & 0.44 \\
\hline CMTp68 & 0.73 & 5.00 & 4.00 & 0.44 & 0.18 & 0.40 \\
\hline CMTp202 & 0.65 & 3.00 & 3.00 & 0.48 & 0.00 & 0.39 \\
\hline CMTp245 & 0.75 & 3.00 & 3.00 & 0.41 & 0.00 & 0.37 \\
\hline CMTp235 & 0.78 & 6.00 & 5.00 & 0.38 & 0.07 & 0.36 \\
\hline CMTp39 & 0.76 & 4.00 & 4.00 & 0.39 & 0.00 & 0.36 \\
\hline CMTp62 & 0.71 & 3.00 & 2.00 & 0.41 & 0.07 & 0.32 \\
\hline CMTp53 & 0.74 & 3.00 & 2.00 & 0.38 & 0.10 & 0.31 \\
\hline СMTp201 & 0.80 & 3.00 & 3.00 & 0.33 & 0.11 & 0.30 \\
\hline CMTp106 & 0.76 & 2.00 & 2.00 & 0.37 & 0.00 & 0.30 \\
\hline СМТр229 & 0.84 & 4.00 & 3.00 & 0.27 & 0.03 & 0.25 \\
\hline CMTp37 & 0.88 & 5.00 & 4.00 & 0.23 & 0.11 & 0.22 \\
\hline CMTp84 & 0.86 & 2.00 & 2.00 & 0.24 & 0.00 & 0.21 \\
\hline CMTp109 & 0.86 & 2.00 & 2.00 & 0.24 & 0.00 & 0.21 \\
\hline CMTp26 & 0.90 & 2.00 & 2.00 & 0.19 & 0.00 & 0.17 \\
\hline Mean & 0.6492 & 5.1154 & 3.9231 & 0.4839 & 0.1332 & 0.4394 \\
\hline
\end{tabular}

dissimilarity matrix values with bootstrapping value of 1000 . PowerMarker software (v3.25) [28] was used to determine polymorphic information content (PIC) [29] and expected heterozygosity [30].

\subsection{PCA of Phenotypic Data}

Patterns of phenotypic variation were examined using PCA in R [31]. Phenotypic data included seed nutrition (oil, protein and fatty acid content) and seed size traits (seed length, seed width, and seed weight) [5]. A correlation matrix between 
principle components and phenotypic traits was calculated, and a 2-dimensional plot was constructed in $\mathrm{R}$ to reveal clustering patterns.

\section{Results}

\subsection{SSR Analysis}

The 26 SSR markers revealed 102 alleles, which ranged in size from 90 bp (marker CMTp176) to $230 \mathrm{bp}$ (marker CMTp53). The allele number per locus ranged from 2 to 7, with an average of 3.92 alleles per locus, while the average gene diversity and heterozygosity across the 26 markers was 0.48 and 0.13 , respectively (Table 1). Polymorphic information content (PIC) ranged from 0.17 to 0.79 , with an average of 0.44 across all loci. Discriminating power was highest in CMTp133 $(\mathrm{He}=0.79 ; \mathrm{PIC}=0.75)$, and lowest in CMTp26 $(\mathrm{He}=0.19 ; \mathrm{PIC}=$ 0.17) (Table 1).

\subsection{Dendrogram}

Ward dendrogram revealed two major clusters (Figure 1). Cluster 1 contained six cultivars of $C$. pepo subsp. texana, which further separated into three sub-clusters 1a, 1b and 1c for Crookneck (Yellow Crookneck and Saffron), Straight-neck (Early Prolific and PI 615086), and Acorn (Honey Bear and Bush Delicata) cultivar

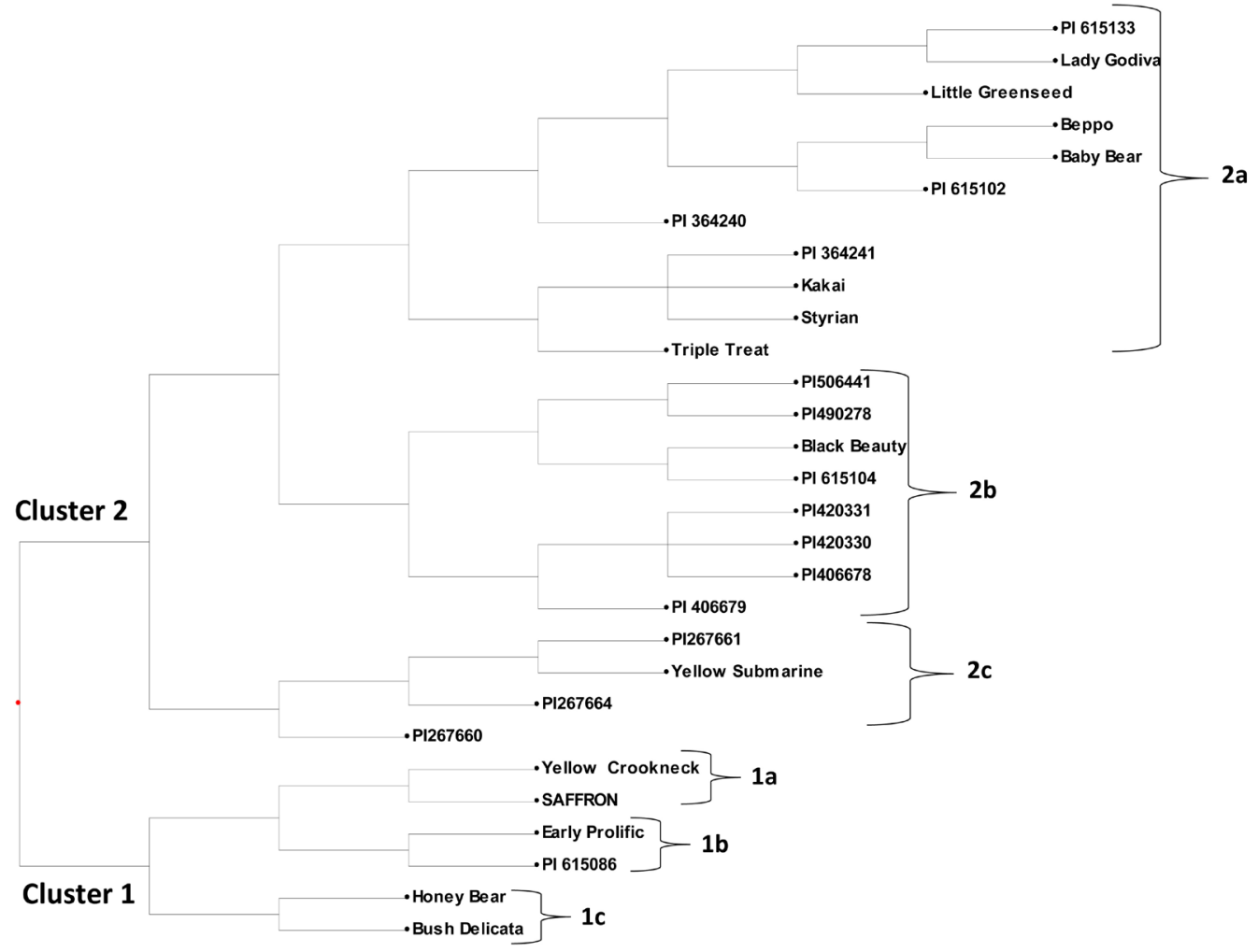

Figure 1. Ward dendrogram showing clustering of the 29 Cucurbita pepo accessions into two main groups. Group 1 consists of three sub-clusters belonging to Crookneck (1a), Straightneck (1b) and Acorn (1c) cultivar-groups of $C$. pepo subspecies texana. Group 2 consists of 23 accessions belonging to C. pepo subspecies texana, that further grouped into three sub-clusters. 
groups, respectively (Figure 1). Cluster 2 consisted of 22 Pumpkin accessions and one Zucchini cultivar (Black Beauty), all belonging to C. pepo subsp. pepo. This cluster further separated into three sub-clusters. The first sub-cluster (2a) consisted of seven commercial reduced-hull Pumpkin cultivars and four PI accessions, one from Austria [PI 615133 (Gleisdorfer Olkurbis)], two from Russia (PI 364240 and PI 364240), and one from U.S. [PI 615102 ("Naked Seed")]. Sub-cluster 2b consisted of Black Beauty Zucchini cultivar and six PI accessions, four from Turkey (PI 420330, PI 420331, PI 406678, and PI 406679) and two from U.S. [PI 490278 ("Butterball") and PI 615104 ("Prostate"). On the other hand, sub-cluster $2 \mathrm{c}$ had the Yellow Submarine Pumpkin cultivar and three PI accessions bred at the University of Connecticut, U.S. (PI 267660, PI 267661 and PI 267664).

\subsection{Genetic Distance}

Genetic distance (GD) among all genotypes ranged from 0.08 to 0.76 (Table 2). Within cluster 1 ( $C$. pepo subsp. texana), the mean GD was 0.45 , and was largest between Acorn and Straightneck cultivar groups (0.50), but lowest between Straightneck and Crookneck (0.35) (Table 3). In cluster 2 (C. pepo subsp. pepo), the mean GD among accessions was 0.28, and was largest between PI 267660 and PI 506441 (0.53), but least between Baby Bear and Beppo cultivars (0.08) (Table 2).

\subsection{Principal Component Analysis}

PCA analysis revealed that the first two principle components (PC) accounted for $65.58 \%$ of the phenotypic variation observed among the accessions (Figure 2 and Table 4). PC 1 had significant correlations with oil (0.4), protein $(-0.18)$, seed weight (0.46), seed length (0.48), seed width (0.45) and palmitic acid (0.34), while PC 2 correlated with oleic $(-0.66)$ and linoleic $(0.67)$ acids (Table 4$)$. The scatter plot revealed that seed size traits (seed weight, seed length and seed width) associated positively with seed oil content, palmitic acid and stearic acid, but negatively with protein, oleic acid and linoleic acid. PCA showed that Beppo and Styrian pumpkin were superior in oil content and seed size traits among the reduced-hull accessions, while Delicata was superior in linoleic acid among the hulled accessions (Figure 2). Based on PC 1 and PC 2, the genotypes clustered into two groups. Group 1 consisted of Pumpkin accessions with reduced-hull ( $C$. pepo subsp. pepo), while group 2 consisted mainly of accessions with hulled seeds (C. pepo subsp. texana).

\section{Discussion}

The mean number of alleles per locus observed in the current study (3.92) falls within the range of that observed (3.0 - 4.3 alleles/locus) across several genetic diversity studies in Cucurbita [16] [17] [32] [33]. The markers used in the current study revealed a high discrimination power (mean PIC of 0.44 ), and clearly 


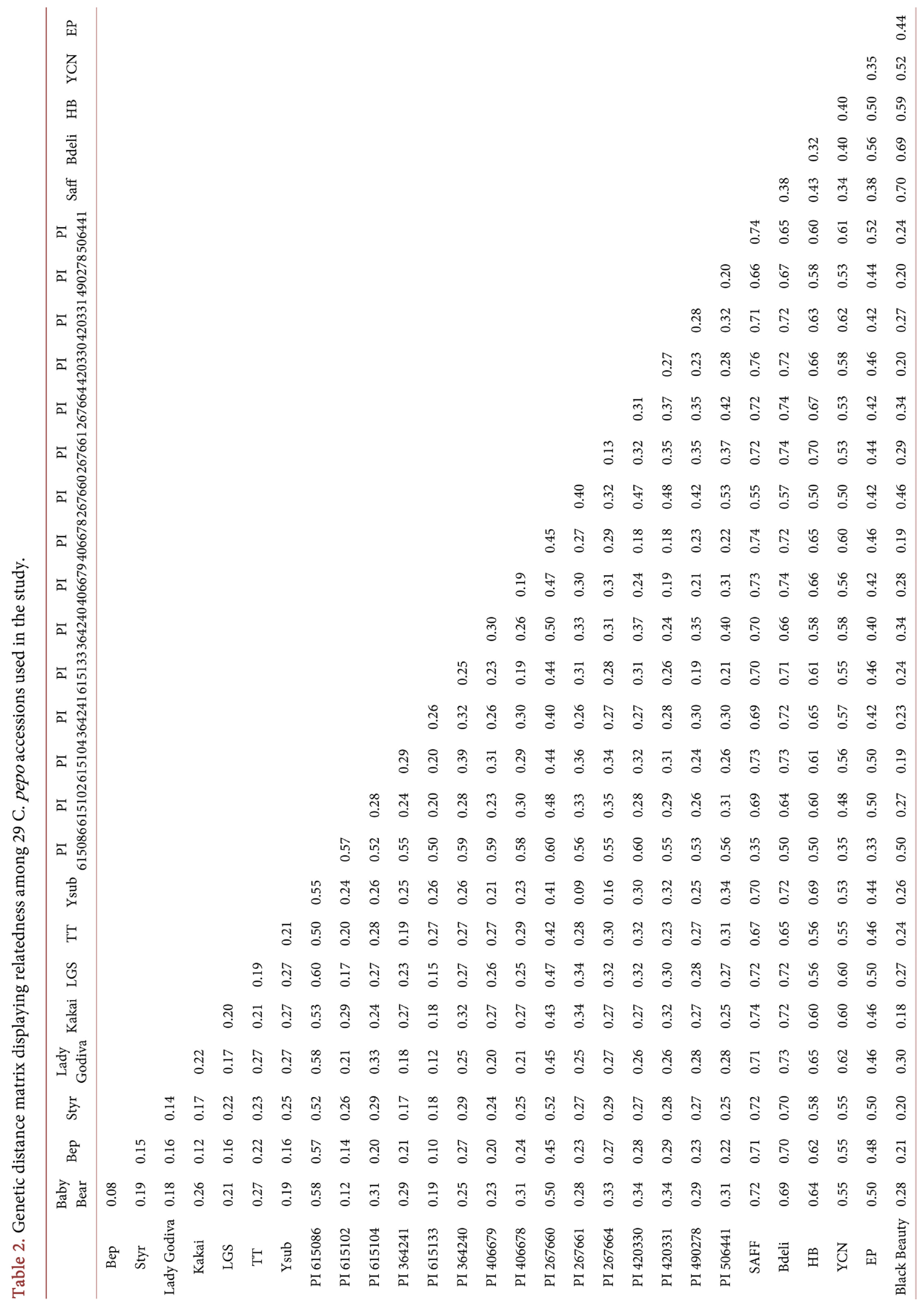




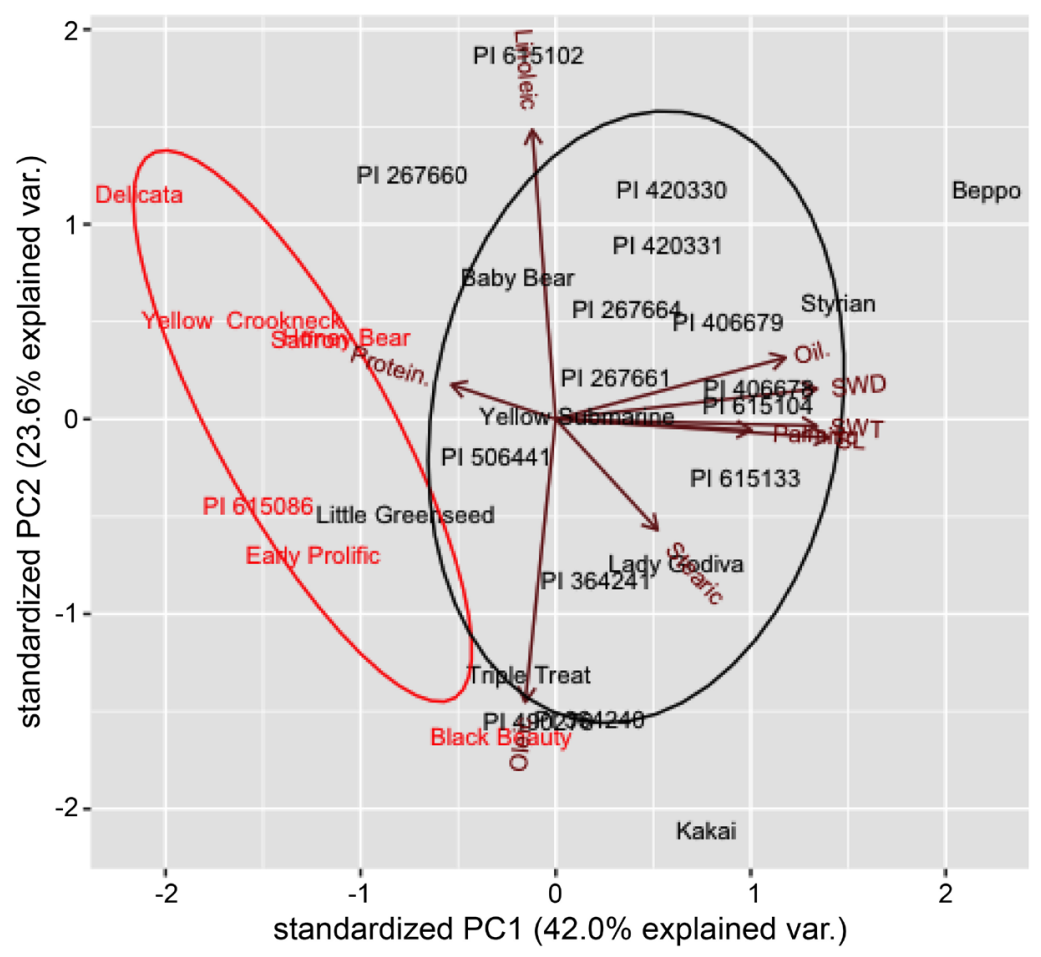

Figure 2. Principal component analysis showing scatterplot for accessions based on seed trait phenotypes. SWT, SL, SWD represent seed weight, seed length and seed width, respectively. Vector length shows the extent of variation explained by each variable. Red and black font indicate accessions with hulled and reduced-hull seed phenotype, respectively.

Table 3. Mean genetic distances among various cultivar-groups (Acorn, Straightneck, Crookneck, Zucchini and Pumpkin) of Cucurbita pepo included in the study.

\begin{tabular}{ccccc}
\hline Cultivar group & Reduced-hull pumpkin & Acorn & Zucchini & Crookneck \\
\hline Acorn & 0.65 & & & \\
Zucchini & 0.25 & 0.64 & & \\
Crookneck & 0.63 & 0.40 & 0.61 & \\
Straightneck & 0.50 & 0.51 & 0.47 & 0.35 \\
\hline
\end{tabular}

Table 4. The principle components, their contribution to the total phenotypic variation and correlations with seed traits.

\begin{tabular}{cccccccccc}
\hline Variable & PC 1 & PC 2 & PC 3 & PC 4 & PC 5 & PC 6 & PC 7 & PC 8 & PC 9 \\
\hline Variation (\%) & 41.97 & 23.61 & 14 & 7.6 & 6.11 & 4.39 & 1.68 & 0.62 & 0.02 \\
Cumulative (\%) & 41.97 & 65.58 & 79.58 & 87.18 & 93.29 & 97.68 & 99.36 & 99.98 & 100 \\
& & & \multicolumn{7}{c}{ Correlation matrix } \\
Oil & 0.4 & 0.14 & -0.24 & -0.07 & 0.17 & 0.77 & -0.08 & -0.33 & 0.01 \\
Protein & -0.18 & 0.08 & 0.72 & 0.08 & -0.48 & 0.39 & -0.2 & -0.02 & 0.02 \\
Seed weight & 0.46 & -0.02 & -0.05 & -0.39 & -0.18 & -0.15 & -0.65 & 0.39 & 0.02 \\
Seed length & 0.48 & -0.04 & 0.14 & -0.02 & -0.17 & 0.13 & 0.66 & 0.51 & -0.03 \\
\hline
\end{tabular}


Continued

\begin{tabular}{cccccccccc}
\hline Seed width & 0.45 & 0.07 & 0.18 & -0.14 & -0.29 & -0.41 & 0.16 & -0.67 & 0.01 \\
Palmitic & 0.34 & -0.03 & 0 & 0.88 & 0.01 & -0.1 & -0.24 & 0.04 & -0.14 \\
Stearic & 0.17 & -0.26 & 0.58 & -0.12 & 0.72 & -0.05 & -0.06 & -0.03 & -0.09 \\
Oleic & -0.05 & -0.66 & -0.12 & -0.08 & -0.22 & 0.11 & -0.01 & -0.1 & -0.68 \\
Linoleic & -0.04 & 0.67 & 0.05 & -0.08 & 0.1 & -0.07 & 0.01 & 0.07 & -0.71 \\
\hline
\end{tabular}

separated the cultivars into two groups corresponding to subspecies pepo and texana of $C$. pepo. These results add to the body of evidence on the usefulness of SSR markers in discriminating accessions to species and subspecies level in $\mathrm{Cu}$ curbita genus [17] [19] [32]. Further separation according to cultivar-groups was observed for cultivars within subspecies texana. Tight clustering within cultivar-groups is expected because the cultivars share common historical pedigree from which they are derived through selection [17] [34]. Similar observations have been reported in numerous phylogenetic studies in Cucurbita [13] [15] [17] [19]. All reduced-hull Pumpkin cultivars grouped in cluster 2, and showed significant variation as evidenced by separation into three sub-clusters. The seven North-American commercial cultivars (Lady Godiva, Little Greenseed, Beppo, Baby Bear, Kakai, Styrian, and Triple Treat) grouped with accessions from Austria and Russia in sub-cluster 2a, thus were likely derived through hybridization and selection from germplasm originating from Asia and Europe. On the other hand, two breeding lines from the U.S. (Butterball and Prostate) may have been derived from accessions in the Mediterranean Basin due to their close association with accessions from Turkey. The origin of Yellow Submarine cultivar is not clear in the current study. However, this cultivar was genetically similar to breeding lines from the University of Connecticut, and is likely derived from a similar pedigree.

PCA analysis supported grouping of accessions into two main clusters corresponding to subspecies pepo and texana, and was consistent with clustering by Ward method. There was a clear delineation in patterns of phenotypic variation between the two groups, with group 1 (subspecies pepo) accessions exhibiting superiority in oil, seed weight, seed length, seed width and palmitic acid. On the other hand, group 2 (subspecies texana) were superior in protein content. The positive association of seed size and oil content in the PCA suggested that the former is an important contributor of oil yield across genotypes, thus breeders may indirectly improve oil content in pumpkin by selecting for larger seeds [5].

Generally, there was a narrow genetic diversity among the reduced-hull Pumpkin accessions and cultivars (mean $\mathrm{GD}=0.28$ ). To maximize genetic diversity, and consequently genetic gain in breeding programs, it is important to select parents most genetically divergent [35]. Among the reduced-hull Pumpkins, PI's 615142 and 615132 had the widest GD, and thus may be used as parents to maximize heterogeneity in the breeding population. Hybridization with cultivars of subspecies texana, such as Acorn, is also necessary to improve the flesh quality 
in reduced-hull pumpkins, particularly for North-American market [12].

Overall, data reported here supports grouping of the accessions into two main clusters corresponding to subspecies pepo and subspecies texana, with all the reduced-hull germplasm clustering within the former. Phenotypic patterns of variation were revealed through PCA, with reduced-hull accessions exhibiting superiority in oil content and seed size. A breeding strategy involving hybridization of reduced-hulled accessions with Acorn type cultivars would improve flesh quality in the former.

\section{Conflicts of Interest}

The authors declare no conflicts of interest regarding the publication of this paper.

\section{References}

[1] Baxter, G.G., Murphy, K. and Paech, A. (2012) The Potential to Produce Pumpkin Seed for Processing in Northeast Victoria. Rural Industries Development Corporation, 11, 5-36.

[2] Fruhwirth, G.O. and Hermetter, A. (2007) Seeds and Oil of the Styrian Oil Pumpkin: Components and Biological Activities. European Journal of Lipid Science and Technology, 109, 1128-1140. https://doi.org/10.1002/ejlt.200700105

[3] Nakić, S.N., Rade, D., Skevin, D., Strucelj, D., Mokrovcak, Z. and Bartolic, M. (2006) Chemical Characteristics of Oils from Naked and Husk Seeds of Cucurbita pepo L. European Journal of Lipid Science and Technology, 108, 963-943. https://doi.org/10.1002/ejlt.200600161

[4] Lazos, E.S. (1992) Certain Functional Properties of Defatted Pumpkin Seed Flour. Plant Foods for Human Nutrition, 42, 257-273. https://doi.org/10.1007/BF02193934

[5] Meru, G., Fu, Y., Leyva, D., Sarnoski, P. and Yagiz, Y. (2018) Phenotypic Relationships among Oil, Protein, Fatty Acid Composition and Seed Size Traits in Cucurbita pepo. Scientia Horticulturae, 233, 47-53. https://doi.org/10.1016/j.scienta.2018.01.030

[6] Wassom, J.J., Mikkelineni, V., Bohn, M.O. and Rocheford, T.R. (2008) QTL for Fatty Acid Composition of Maize Kernel Oil in Illinois High Oil $\times$ B73 Backcross-Derived Lines. Crop Science, 48, 69-78. https://doi.org/10.2135/cropsci2007.04.0208

[7] Lelley, T., Loy, B.L. and Murkovic, M. (2009) Hull-Less Oil Seed Pumpkin. In: Vollmann, J. and Rajcan, I., Eds., Oil Crops, Handbook of Plant Breeding, Springer, New York, 469-492. https://doi.org/10.1007/978-0-387-77594-4_16

[8] Nesaretnam, K., Gomez, P.A., Selvaduray, K.R. and Razak. G.A. (2007) Tocotrienol Levels in Adipose Tissue of Benign and Malignant Breast Lumps in Patients in Malaysia. Asia Pacific Journal of Clinical Nutrition, 16, 498-504.

[9] Stevenson, D.G., Eller, F.J., Wang, L., Jane, J.L., Wang, T. and Inglett, G.E. (2007) Oil and Tocopherol Content and Composition of Pumpkin Seed Oil in 12 Cultivars. Journal of Agricultural and Food Chemistry, 55, 4005-4013. https://doi.org/10.1021/jf0706979

[10] Thompson, G.R. and Grundy, S.M. (2005) History and Development of Plant Sterol and Stanol Esters for Cholesterol-Lowering Purposes. American Journal of Cardiology, 96, 3-9. https://doi.org/10.1016/j.amjcard.2005.03.013 
[11] Loy, J.B. (2004) Morpho-Physiological Aspects of Productivity and Quality in Squash and Pumpkins (Cucurbita spp.). Critical Reviews in Plant Sciences, 23, 337-363. https://doi.org/10.1080/07352680490490733

[12] Meru, G. and Fu, Y. (2018) Yield and Horticultural Performance of Naked-Seed Pumpkin in South Florida. EDIS, HS1323. https://edis.ifas.ufl.edu/hs1323

[13] Decker, D.S. (1985) Numerical Analysis of Allozyme Variation in Cucurbita pepo. Economic Botany, 39, 300-309. https://doi.org/10.1007/BF02858800

[14] Decker, D.S., Staub, J.E., Chung, S.M., Nakata, E. and Quemada, H.D. (2002) Diversity in Free-Living Populations of Cucurbita pepo (Cucurbitaceae) as Assessed by Random Amplified Polymorphic DNA. Systematic Botany, 27, 19-28.

[15] Ferriol, M., Picó, B. and Nuez, F. (2003) Genetic Diversity of a Germplasm Collection of Cucurbita pepo Using SRAP and AFLP Markers. Theoretical and Applied Genetics, 107, 271-282. https://doi.org/10.1007/s00122-003-1242-Z

[16] Formisano, G., Roig, C., Esteras, C., Ercolano, M.R., Nuez, F., Monforte, A.J. and Picó, M.B. (2012) Genetic Diversity of Spanish Cucurbita pepo Landraces: An Unexploited Resource for Summer Squash Breeding. Genetic Resources and Crop Evolution, 59, 1169-1184. https://doi.org/10.1007/s10722-011-9753-y

[17] Gong, L., Paris, H.S., Nee, M.H., Stift, G., Pachner, M., Vollmann, J. and Lelley, T. (2012) Genetic Relationships and Evolution in Cucurbita pepo (Pumpkin, Squash, Gourd) as Revealed by Simple Sequence Repeat Polymorphisms. Theoretical and Applied Genetics, 124, 875-891. https://doi.org/10.1007/s00122-011-1752-Z

[18] Paris, H.S., Doron-Faigenboim, A., Reddy, U.K., Donahoo, R. and Levi, A. (2015) Genetic Relationships in Cucurbita pepo (Pumpkin, Squash, Gourd) as Viewed with High Frequency Oligonucleotide-Targeting Active Gene (HFO-TAG) Markers. Genetic Resources and Crop Evolution, 62, 1095-1111. https://doi.org/10.1007/s10722-015-0218-6

[19] Paris, H.S., Yonash, N., Portnoy, V., Mozes-Daube, N., Tzuri, G. and Katzir, N. (2003) Assessment of Genetic Relationships in Cucurbita pepo (Cucurbitaceae) Using DNA Markers. Theoretical and Applied Genetics, 106, 971-978. https://doi.org/10.1007/s00122-002-1157-0

[20] Hodel, R.G.J., Gitzendanner, M.A., Germain-Aubrey, C.C., Liu, X., Crowl, A.A., Sun, M., Landis, J.B., Segovia-Salcedo, M.C., Douglas, N.A., Chen, S., Soltis, D.E. and Soltis, P.S. (2016) A New Resource for the Development of SSR Markers: Millions of Loci from a Thousand Plant Transcriptomes. Applications in Plant Sciences, 4, Article ID: 1600024. https://doi.org/10.3732/apps.1600024

[21] Powell, W., Morgante, M., Andre, C., Hanafey, M., Vogel, J., Tingey, S. and Rafalski, A. (1996) The Comparison of RFLP, RAPD, AFLP and SSR (Microsatellite) Markers for Germplasm Analysis. Molecular Breeding, 2, 225-238. https://doi.org/10.1007/BF00564200

[22] Dagnelie, P. (1975) Multivariate Statistical Analysis. Les presses agronomiques de Gembloux, Gembloux.

[23] Islam, M.R. (2004) Genetic Diversity in Irrigated Rice. Pakistan Journal of Biological Sciences, 2, 226-229. https://doi.org/10.3923/pjbs.2004.226.229

[24] Gong, L., Stift, G., Kofler, R., Pachner, M. and Lelley, T. (2008) Microsatellites for the Genus Cucurbita and an SSR-Based Genetic Linkage Map of Cucurbita pepo L. Theoretical and Applied Genetics, 117, 37-48. https://doi.org/10.1007/s00122-008-0750-2

[25] Blacket, M.J., Robin, C., Good, R.T., Lee, S.F. and Miller, A.D. (2012) Universal Primers for Fluorescent Labelling of PCR Fragments-An Efficient and Cost-Effective 
Approach to Genotyping by Fluorescence. Molecular Ecology Resources, 12, 456-463. https://doi.org/10.1111/j.1755-0998.2011.03104.x

[26] Perrier, X. and Jacquemoud-Collet, J. (2006) Dissimilarity Analysis and Representation for Windows (DARwin). CIRAD, France, 15 November 2017.

http://darwin.cirad.fr/darwin

[27] Ward, J.H. (1963) Hierarchical Grouping to Optimize an Objective Function. Journal of the American Statistical Association, 58, 236-244. https://doi.org/10.1080/01621459.1963.10500845

[28] Liu, K. and Muse, S.V. (2005) PowerMarker: An Integrated Analysis Environment for Genetic Marker Analysis. Bioinformatics, 21, 2128-2129. https://doi.org/10.1093/bioinformatics/bti282

[29] Botstein, D., White, R.L., Skolnick, M. and Davis, R.W. (1980) Construction of a Genetic Linkage Map in Man Using Restriction Fragment Length Polymorphisms. Amer. Journal of Human Genetics, 32, 314-331.

[30] Weir, B.S. (1996) Genetic Data Analysis II Methods for Discrete Population Genetic Data. Sinauer Associates Inc., Sunderland, MA.

[31] R Core Team (2016) R: A Language and Environment for Statistical Computing. R Foundation for Statistical Computing. https://www.R-project.org/

[32] Gong, L., Paris, H.S., Stift, G., Pachner, M., Vollmann, J. and Lelley, T. (2013) Genetic Relationships and Evolution in Cucurbita as Viewed with Simple Sequence Repeat Polymorphisms: The Centrality of C. okeechobeensis. Genetic Resources and Crop Evolution, 60, 1531-1546. https://doi.org/10.1007/s10722-012-9940-5

[33] Verdone, M., Rao, R., Coppola, M. and Corrado, G. (2018) Identification of Zucchini Varieties in Commercial Food Products by DNA Typing. Food Control, 84, 197-204. https://doi.org/10.1016/j.foodcont.2017.07.039

[34] Paris, H.S. (2001) History of the Cultivar-Groups of Cucurbita pepo. In: Janick, J., Ed., Horticultural Reviews, John Wiley \& Sons, Inc., Oxford, 71-170. https://doi.org/10.1002/9780470650783.ch2

[35] Michael, V., Moon, P. Fu, Y. and Meru, G. (2019) Genetic Diversity among Accessions of Cucurbita pepo Resistant to Phytophthora Crown Rot. HortScience, 54, 17-22. https://doi.org/10.21273/HORTSCI13506-18 